\title{
Lower nodule biomass with increased nitrogenase efficiency in Robinia pseudoacacia seedlings when grown under low soil phosphorus conditions
}

\author{
Lindsay A. McCulloch ${ }^{1}$ (D) Stephen Porder ${ }^{1}$
}

Received: 28 May 2020 / Accepted: 16 September 2020 / Published online: 7 October 2020

(c) The Author(s) 2020 OPEN

\begin{abstract}
Symbiotic nitrogen $(\mathrm{N})$ fixation is the largest non-anthropogenic $\mathrm{N}$ input to many terrestrial ecosystems. The energetic expense of symbiotic $N$ fixation suggests soil phosphorus $(P)$ availability may regulate symbiotic nitrogen fixation directly through nodule development and function, and/or indirectly through plant growth. Since P availability is heterogenous in the landscape, we sought to understand if symbiotic nitrogen fixation responds to both $\mathrm{P}$ availability and heterogeneity. To test how $\mathrm{P}$ availability affects symbiotic nitrogen fixation, we grew Robinia pseudoacacia seedlings under high $\left(8.1 \mathrm{~g} \mathrm{P} \mathrm{m}^{-2}\right)$ and low $\left(0.2 \mathrm{~g} \mathrm{P} \mathrm{m}^{-2}\right)$ conditions. Soil $\mathrm{P}$ heterogeneity was simulated by splitting roots into soil patches receiving $P$ or no-P fertilizer. At the whole plant level, $P$ availability limited seedling and nodule biomass. However, the low $P$ treatment had higher nitrogenase efficiency (acetylene reduced (AR) $\mathrm{g}^{-1}$ nodule; a nodule efficiency proxy). High $P$ seedlings had significantly more root and nodule biomass in the patches directly receiving $P$ fertilizer, but patch proliferation was absent in the low $\mathrm{P}$ treatment. $\mathrm{AR} \mathrm{g}^{-1}$ seedling did not differ between $\mathrm{P}$ treatments, suggesting $\mathrm{P}$ indirectly limited symbiotic nitrogen fixation through plant growth, rather than directly limiting symbiotic nitrogen fixation. This relatively consistent $\mathrm{AR}^{-1}$ seedling across treatments demonstrates the ability of seedlings to respond to low $\mathrm{P}$ conditions with increased nitrogenase efficiency.
\end{abstract}

Keywords Split-root $\cdot$ nutrient patches $\cdot$ Symbiotic nitrogen fixation $\cdot$ Black locust $\cdot$ P fertilization

\section{Introduction}

The factors that determine when and where symbiotic nitrogen fixation (SNF) occurs have been an area of inquiry for decades, and influence the productivity of both agricultural and natural ecosystems [1-3]. In association with their host plants, symbiotic nitrogen (N)-fixing bacteria convert atmospheric $\mathrm{N}$ into a form of readily available $\mathrm{N}$ for plant-use, adding reactive $\mathrm{N}$ to ecosystems through the plants they help to fertilize.
$\mathrm{N}$-fixing Rhizobia reside in root nodules on plants in the Fabaceae family (hereafter legumes) and receive carbon (C) in exchange for $\mathrm{N}$ [4]. While this relationship has been explored for over a century [5], and the rate at which SNF occurs varies widely in response to abiotic factors, such as soil nutrient, light and water availability [6-12]. The availability of these resources in the environment is often heterogenous [13-18]. An understanding how legumes and SNF rates are influenced by this resource

Electronic supplementary material The online version of this article (https://doi.org/10.1007/s42452-020-03518-z) contains supplementary material, which is available to authorized users.

Lindsay A. McCulloch, Lindsay_McCulloch@brown.edu | 'Department of Ecology and Evolutionary Biology, Brown University, Providence, RI, USA. 
heterogeneity at the plant-scale will increase our understanding of this globally important process.

Theory and empirical experiments suggest SNF can be limited by soil phosphorus (P), which is important for legume growth and Rhizobia activity [4, 9, 19-21]. The exact mechanisms by which $P$ limits SNF remains unresolved, with some evidence of direct effects to nodule development and function observed under low $P$ conditions, as well as, indirect SNF limitation by lower plant growth in other studies $[8,9,21-25]$. P fertilization often increases SNF in shadehouse-grown seedlings $[8,9,22,23,26-29]$, but this effect is not universal and may depend on the plant species or genotype $[9,11,12$, $25,30]$. Much of the previous work has been on agricultural legumes. For example, the SNF response to low $P$ conditions in the agricultural legume Phaseolus vulgaris depended on genotype [11, 12], and some genotypes had increased SNF efficiency under low P conditions [12]. Similar results of higher nitrogenase efficiency under $P$ deprived conditions were found in the wild legume, Acacia mangium [31]. Thus, previous studies have found a myriad of SNF responses to $P$ availability and our understanding of how $P$ availability may affect SNF, especially in non-agricultural legumes, continues to evolve.

The difference between direct and indirect $P$ limitation to SNF might be further complicated by how legumes and their symbionts respond to heterogenous soil nutrients. For example, if plant growth is limited by $\mathrm{P}$, and a root tip encounters a patch of high $\mathrm{P}$ soil, does SNF (nodule biomass and/or nitrogenase activity) proliferate on that root? Or is there a SNF response throughout the root system if this process is regulated by the overall nutrient status of the plant? It has long been known that when plants grow under nutrient limitation, roots can proliferate in patches of high nutrient availability [14, 32]. Proliferation of SNF specifically has been observed in response to water availability and bacterial strains [33,34]. A previous study demonstrated localized nodule proliferation in legume seedlings exposed to patchy water availability [33]. Similarly, higher SNF was observed on roots that were exposed to preferred bacterial strains [34]. However, whether SNF responds in a similar manner to soil nutrient patches has not been, to our knowledge, previously examined. If SNF is regulated at the whole plant level, there may be no upregulation of SNF where a patch of soil P is encountered. Upregulation may not occur because plant growth is limited by $\mathrm{P}$, or the upregulation of SNF will be throughout the root system and not at the specific point the root system encounters $P$. In contrast, if SNF is controlled at the localized root level, then an increase in SNF would occur where a soil nutrient patch is encountered, even when whole-plant growth is limited by P.
As a starting framework, we consider two end members hypotheses that describe the potential SNF response to patches of soil nutrients: generalized or localized. We hypothesize that legumes could have a "generalized response" to favorable soil nutrient patches (e.g. high nutrients) by increasing SNF throughout the root system (not just in that patch of soil). In contrast, legumes could have a "localized response" in the case when nodules proliferate only in a patch of soil with favorable conditions. We hypothesize that localized responses will be more prevalent in low nutrient conditions, when limitation to plant growth by nutrients is also pronounced.

We test these hypotheses using a split-root greenhouse study for seedlings of a common $\mathrm{N}$-fixing woody legume (Robinia pseudoacacia) that were grown under high and low $\mathrm{P}$ fertilization. To test for localized vs. generalized responses of SNF, we split the roots of each seedling in both high and low $\mathrm{P}$ treatments into separate pots (to simulate patches of soil nutrients), which received either P-fertilizer or no P-fertilizer. We then asked: (1) was plant growth and SNF limited by soil P, and if so, was SNF directly or indirectly limited by P? (2) Did SNF for an individual plant differ between roots growing in P-fertilized vs. no P-fertilized pots? (3) Did SNF response (local vs. generalized) vary between seedlings grown in the high vs. low $P$ fertilizer treatments? We hypothesize, based on root proliferation experiments [32] and previous split-root SNF experiments [33,34], that roots and nodules would proliferate in fertilized patches, particularly under overall low $\mathrm{P}$ conditions.

\section{Material and methods}

\subsection{Split-Root Design}

The results we report below are from roots in high vs. low $P$ treatments with roots split between patches of soil with and without $P$ additions. However, we initially implemented a four-way split root greenhouse experiment manipulating both $\mathrm{P}$ and molybdenum (Mo), as Mo is an important element for the nitrogenase enzyme. Roots from each plant were split between treatments of + P-Mo, + P + Mo, $-\mathrm{P}-\mathrm{Mo}$, and $-\mathrm{P}+$ Mo. We saw no effects of Mo on any measured response variables. Further, because it is not likely our seedlings depleted the Mo seed reserve during the duration of this study and Mo is easily translocated through the plant [35], we describe results for two types of soil patches-with $(+\mathrm{P}-\mathrm{Mo},+\mathrm{P}+\mathrm{Mo})$ and without $\mathrm{P}$ fertilizer $(-\mathrm{P}-\mathrm{Mo},-\mathrm{P}+\mathrm{Mo})$.

We chose Robinia pseudoacacia (common name of Black locust) as our study species as it is a fast-growing, deciduous, and drought tolerant legume tree species that was 
amenable to split root experiments (USDA, 2018). Seeds were obtained from Sheffield's Seed Company ((https ://sheffields.com/seeds-for- sale/Robinia/pseudoacacia///////1302//Black-Locust,-Yellow-Locust, False-Acacia). Seeds were scarified with sulfuric acid and individually placed in Root $\operatorname{Riot}^{\circledR}$ cubes to support the seedlings once the root system was split. Seedlings were grown in a growth chamber at $22^{\circ} \mathrm{C}$ for $12 \mathrm{~h}$ per day for 1 month and received no $\mathrm{N}$ fertilizer. After a month, the seedlings were transferred to the greenhouse at Brown University (Providence, $\mathrm{RI}, \mathrm{USA}$ ) and left to adjust to greenhouse conditions for 1 week.

In June 2017, after the adjustment period to greenhouse conditions, the roots from each of 70 seedlings were randomly split into 4 separate Cone-tainers ( 2 of which had $P$ fertilizer added and 2 of which did not). We split the roots after about 1 month because at least 70 seedlings had 4 roots at least $5 \mathrm{~cm}$ in length emerging from the Root Riot $^{\oplus}$ cubes. There were no nodules present at the time of root splitting and each root section was inoculated with a slurry of inoculum (produced by grinding up nodules excised from other R. pseudoacica plants sourced from the Menge Lab at Columbia University) the day after root splitting and replanting. All roots were placed in $100 \%$ silica sand to avoid exposing the seedlings to nutrients outside of fertilizer treatments. All seedlings received a Hoagland solution with no $\mathrm{N}$ and either low $\mathrm{P}\left(0.2 \mathrm{~g} \mathrm{~m}^{-2}\right.$ over the course of the experiment, $n=30)$ or high $\mathrm{P}\left(8.1 \mathrm{~g} \mathrm{~m}^{-2}\right.$, $n=29$; see Table $\mathrm{S} 1$ for details on Hoagland solution composition). However, only 2 of the 4 root sections directly received fertilizer with $\mathrm{P}$ (Fig. 1). The other 2 root sections of a given plant received the same Hoagland solution but with no $P$ (Fig. 1). To test if response variables were influenced by patches in soil nutrients and not only responding to a split-root effect, we grew high and low $P$ controls (low $\mathrm{P} n=5$ high $\mathrm{P} n=5$ ). Controls received the same amount of $\mathrm{P}$ as their respective $\mathrm{P}$ treatment (high or low), but all four containers of a given plant received equal amounts of either high or low P (Fig. S1).

In order to harvest the seedlings before leaves were shed in the fall, we collected the plants 4 months after treatments began. SNF was measured on each root section immediately after harvest (see Symbiotic nitrogen fixation measurements), and then nodules were dried on silica gel for dry mass estimates. Biomass (leaves, shoots, roots) were measured after the plants were dried at $60^{\circ} \mathrm{C}$ for at least $48 \mathrm{~h}$. Leaf, shoot, and root biomass were combined to estimate final seedling biomass (hereafter "total biomass").

\subsection{Symbiotic nitrogen fixation measurements}

We harvested each of the 4 root sections of a plant separately and immediately performed acetylene reduction assays (ARA) if nodules were present $[36,37]$. For each ARA, we randomly selected 10 nodules from each root section and placed them in a $60 \mathrm{~mL}$ gas tight jar fitted with a septum and incubated them for one hour in an atmosphere of $10 \%$ acetylene. We made acetylene from calcium carbide each day. We used both controls and blanks to established background ethylene produced by the sample or present in the acetylene, respectively. For controls of each sample, we randomly selected 10 additional nodules and placed

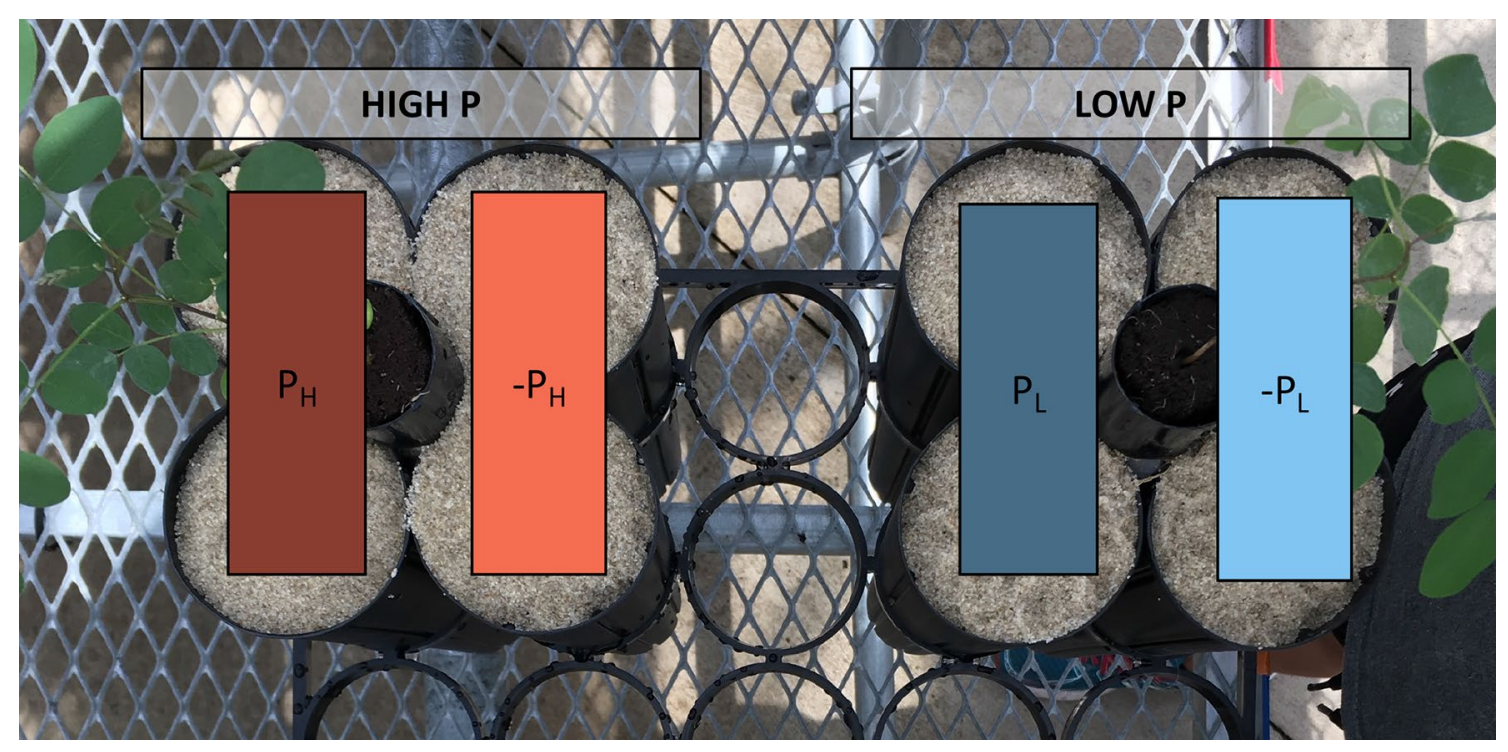

Fig. 1 Image of split-root experimental design for high and low $\mathrm{P}$ plants. Two root sections of a seedling received $P$ fertilizer directly $\left(\mathrm{P}_{\mathrm{H}}\right.$ and $\left.\mathrm{P}_{\mathrm{L}}\right)$, the amount of $\mathrm{P}$ in those fertilizer treatments was determined by whether the seedling was in a high or low $\mathrm{P}$ treatment group. The other two root sections of a seedling received fertilizer with no $P\left(-P_{H}\right.$ and $\left.-P_{L}\right)$ 
them in another $60 \mathrm{~mL}$ gas tight jar to incubate for one hour without adding acetylene. For blanks, we added acetylene to jars with no nodules. All gas samples were stored in pre-evacuated gas-tight Labco Exetainers vials and analyzed for ethylene concentration on a Shimadzu GC-2014 gas chromatograph equipped with a flame ionization detector $\left(330^{\circ} \mathrm{C}\right)$ and Poropak-T column $\left(80^{\circ} \mathrm{C}\right)$ at Brown University.

We report four main SNF response variables in this study: nodule mass (g), nitrogenase efficiency $\left(\mu \mathrm{mol} \mathrm{C}_{2} \mathrm{H}_{4}\right.$ $\mathrm{h}^{-1} \mathrm{~g}^{-1}$ nodule), acetylene reduced per gram of seedling $\left(\mu \mathrm{mol} \mathrm{C}_{2} \mathrm{H}_{4} \mathrm{~h}^{-1} \mathrm{~g}^{-1}\right.$ ) and acetylene reduced per gram of root section ( $\mu \mathrm{mol} \mathrm{C}_{2} \mathrm{H}_{4} \mathrm{~h}^{-1} \mathrm{~g}^{-1}$ ). We also estimated $A R$ per seedling ( $\mu \mathrm{mol} \mathrm{C}_{2} \mathrm{H}_{4} \mathrm{~h}^{-1}$ ) by multiplying nitrogenase efficiency and total nodule biomass. We used AR per $\mathrm{g}^{-1}$ seedling to compare whole seedlings in the high and low $P$ treatments and AR per $\mathrm{g}^{-1}$ root section to compare root sections in patches of soil nutrients under high and low $P$ treatments. We used these data to explore if $P$ limitation leads to overall lower $A R$, and if this is driven by direct SNF limitation (lowered nodule biomass or nitrogenase efficiency) or indirect limitation (lower AR associated with lower plant biomass rather than a decrease in $\mathrm{AR}^{-1}$ of seedling or root section, or nitrogenase activity).

For the split-root analyses we report these variables for each treatment group $\left(\mathrm{P}_{\mathrm{H}},-\mathrm{P}_{\mathrm{H}}, \mathrm{P}_{\mathrm{L}^{\prime}}-\mathrm{P}_{\mathrm{L}}\right) . \mathrm{P}_{\mathrm{H}}$ indicates root sections receiving $P$ fertilizer in seedlings growing under high $P$ conditions. $-P_{H}$ indicates root sections receiving fertilizer that contained no $P$ in seedlings growing under high $P$ conditions. Seedlings growing in the low $P$ treatment also had root sections directly exposed to $P$ fertilizer $\left(P_{L}\right)$ and root sections exposed to fertilizer that contained no $P\left(-P_{L}\right)$. For the split-root results we also reported average mass per nodule to examine if differences in nodule biomass between treatments is driven by the number or the size of the nodules. We assessed localized versus generalized responses by testing whether there were differences between P-fertilized and no P-fertilized root sections of the same seedlings in a given $P$ treatment (high versus low). Finally, we reported total biomass ( $g$ ) for whole plant results and root biomass ( $\mathrm{g}$ ) for spilt-root results to determine treatment effects on plant growth.

\subsection{Statistical analyses}

We tested the assumptions of normality and homoscedasticity for t-tests using Shapiro-Wilk test and the Levene's test, respectively. Since these assumptions were not met, we used non-parametric Wilcox rank sum tests to test for differences in total biomass (g), nodule mass (g), nitrogenase efficiency ( $\mu \mathrm{mol} \mathrm{C}_{2} \mathrm{H}_{4} \mathrm{~h}^{-1} \mathrm{~g}^{-1}$ nodule), and acetylene reduced (AR) per $\mathrm{g}^{-1}$ seedling $\left(\mu \mathrm{mol}_{2} \mathrm{H}_{4} \mathrm{~h}^{-1} \mathrm{~g}^{-1}\right)$ between our high and low $P$ fertilization treatments.

In order to understand how roots responded to patchy nutrient supply when grown under high or low $\mathrm{P}$ conditions, we analyzed the responses of root sections in the four $\mathrm{P}$ treatments $\left(\mathrm{P}_{\mathrm{H}},-\mathrm{P}_{\mathrm{H}}, \mathrm{P}_{\mathrm{L}},-\mathrm{P}_{\mathrm{L}}\right)$ using Kruskal-Wallis tests to compare root biomass (g), nodule mass (g), nitrogenase efficiency ( $\mu \mathrm{mol} \mathrm{C}_{2} \mathrm{H}_{4} \mathrm{~h}^{-1} \mathrm{~g}^{-1}$ nodule), and acetylene reduced (AR) $\mathrm{g}^{-1}$ root section $\left(\mu \mathrm{mol} \mathrm{C}_{2} \mathrm{H}_{4} \mathrm{~h}^{-1} \mathrm{~g}^{-1}\right.$ biomass). We used Pairwise Wilcoxon Rank Sum tests for post-hoc comparisons to determine pairwise differences between treatment groups. All statistical analyses were performed in $\mathrm{R}$ version 3.6.2.

\section{Results}

\subsection{Whole plant (high vs. low P)}

Seedlings in the high $\mathrm{P}$ treatment exhibited significantly higher total biomass $(P=0.005$, Fig. $2 \mathrm{a})$, and total nodule mass $(P<0.001$, Fig. 2b). However, nitrogenase efficiency ( $\mu \mathrm{mol} \mathrm{C}_{2} \mathrm{H}_{4} \mathrm{~h}^{-1} \mathrm{~g}^{-1}$ nodule) was significantly higher in the low $P$ treatment ( $P=0.003$, Fig. $2 \mathrm{c}$ ), and thus the AR $\mathrm{g}^{-1}$ seedling did not differ between high and low $P$ treatments $(P=0.39$, Fig. $2 \mathrm{~d})$. Total nodule biomass was twice as high in the high $P$ treatment $(P<0.001)$, leading to the AR per seedling being $40 \%$ higher than in the low $P$ treatment $(P=0.02)$.

The whole plant controls, whose roots were split into four pots that all received the same nutrient treatment [either high $\mathrm{P}(n=5)$ or low $\mathrm{P}(n=5)$ ] also indicated $\mathrm{P}$ limitation to growth and nodule mass in the low $P$ treatment. High $P$ controls had higher total biomass $(P=0.056)$ and total nodule mass $(P=0.059)$ than low $P$ controls. However, $\mathrm{AR}^{-1}$ seedling and nitrogenase efficiency were not significantly different between high and low $P$ treatment groups ( $P=0.79, P=1$, respectively). Controls had far fewer samples in each treatment $(n=5)$ than in the rest of the experiment ( $n=29$ and 30).

\subsection{Split-root analysis}

While P limitation to seedling growth and SNF was established at the whole plant level, we did not observe localized responses to patches of $P$ in the low $P$ treatment. Within low $P$ seedlings, root biomass $(P=0.93)$, total nodule biomass ( $P=0.88)$, nitrogenase efficiency $(P=0.94)$, and $\mathrm{AR} \mathrm{g}^{-1}$ root section $(P=0.99)$ did not differ between the root sections directly receiving low $P$ fertilizer $\left(P_{L}\right)$ and root sections not receiving fertilizer directly $\left(-P_{L}\right.$, Fig. 3a-d).

In contrast, there was significantly higher root biomass in root sections receiving high $P$ fertilizer $\left(P_{H}\right)$ compared 


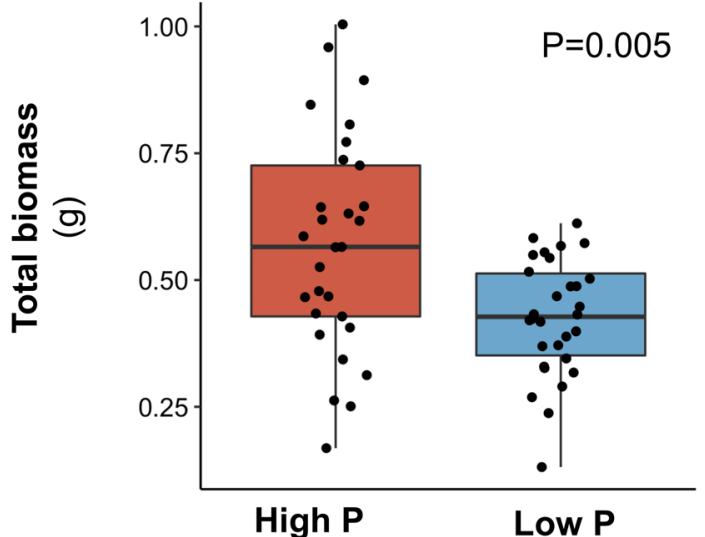

C

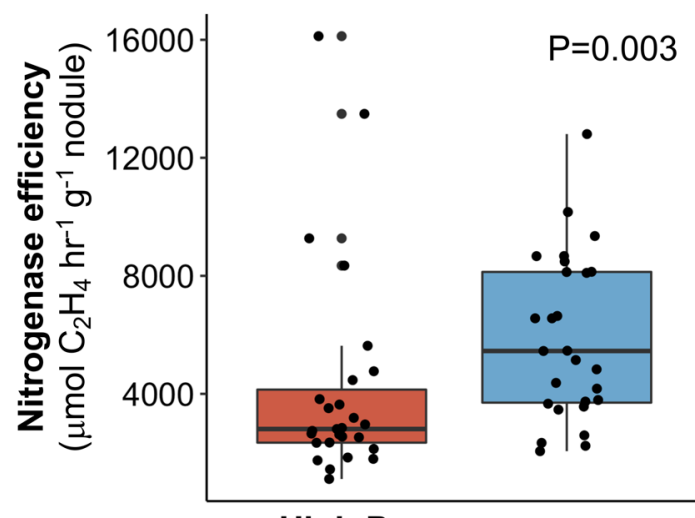

High P b

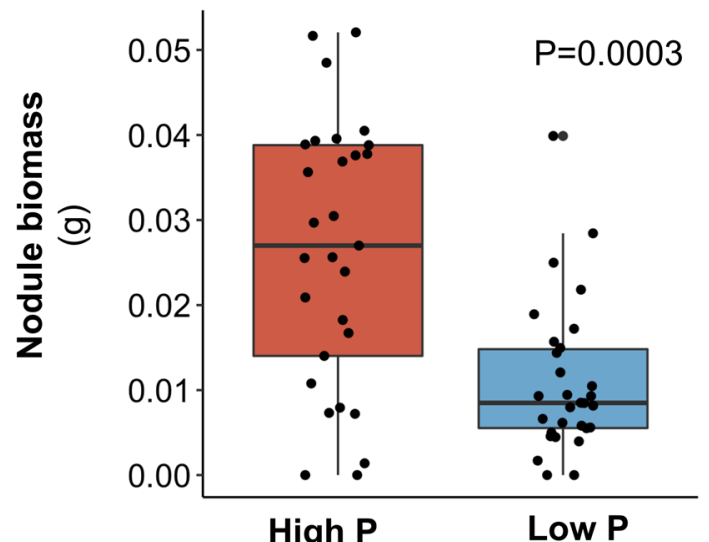

d

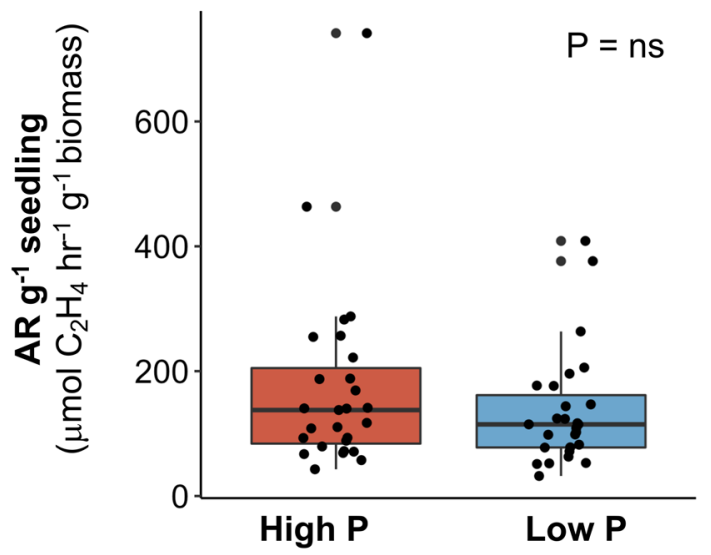

quartile range, the line is the median, and the whiskers are the lowest or highest value within 1.5 times the interquartile range. Points represent the values from individual seedlings within each treatment. Points were jittered within treatment to prevent overlap

patches when seedlings were grown under $\mathrm{P}$ abundance or limitation. We observed a significant localized proliferation of root growth ( $P=0.010$, Fig. 3a) and total nodule biomass $(P=0.006$, Fig. $3 b)$ in the root sections of the high $P$ plants that directly received fertilizer $\left(\mathrm{P}_{\mathrm{H}}\right)$. However, there were no differences among the other 3 treatments $\left(-\mathrm{P}_{\mathrm{H}^{\prime}}\right.$ $\left.P_{L},-P_{L}\right)$, even though seedlings attached to root sections receiving the $-P_{H}$ treatment were receiving substantially more $P$ than those in the $P_{L}$ and $-P_{L}$ treatments. The average biomass per nodule did not vary significantly within high $(P=0.94)$ or low $(P=0.27) \mathrm{P}$ treatments, but $\mathrm{P}_{\mathrm{H}}$ and $-P_{H}$ had nodules that were on average two times larger than nodules from the $P_{L}$ and $-P_{L}$ root sections $(P=0.001)$.

The root biomass, total nodule biomass, and nitrogenase efficiency of the root sections receiving no fertilizer $\left(-P_{H}\right.$ and $\left.-P_{L}\right)$ were also not different from one another $(P=0.928, P=0.781, P=0.246$, respectively). Further there was no large difference between the four treatments if there were differences in SNF responses to nutrient 

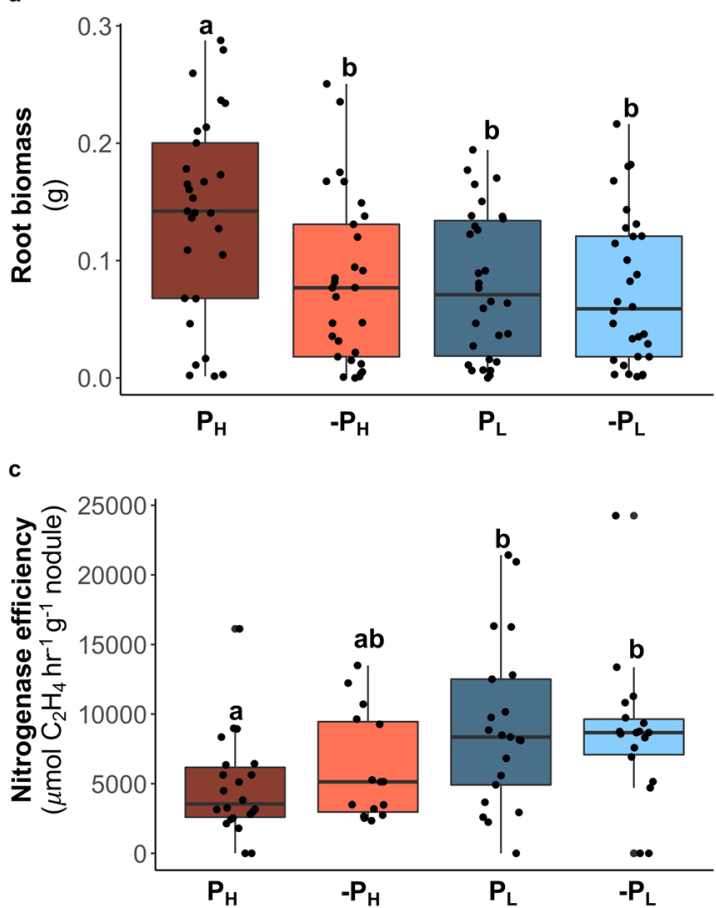

Fig. 3 Comparison of response variables across $\mathrm{P}$ split-root treatments $\left(\mathrm{P}_{\mathrm{H}},-\mathrm{P}_{\mathrm{H}}, \mathrm{P}_{\mathrm{L}},-\mathrm{P}_{\mathrm{L}}\right)$ for a root biomass expressed in grams, b nodule biomass expressed in grams, c nitrogenase efficiency expressed in $\mu \mathrm{mol} \mathrm{C}_{2} \mathrm{H}_{4} \mathrm{~h}^{-1} \mathrm{~g}^{-1}$ nodule, $\mathbf{d}$ acetylene reduced (AR) per gram of root section $\mu \mathrm{mol}_{2} \mathrm{H}_{4} \mathrm{~h}^{-1} \mathrm{~g}^{-1}$ biomass. Different letters signify significant differences $(P<0.05)$ between treatment

when nodule biomass was normalized by root biomass $\left(\mathrm{P}_{\mathrm{H}^{\prime}}-\mathrm{P}_{\mathrm{H}}, \mathrm{P}_{\mathrm{L}^{\prime}}-\mathrm{P}_{\mathrm{L}} ; P=0.08\right)$. However, nitrogenase efficiency was higher in the root sections associated with the low $P$ plants $\left(P_{L}\right.$ and $\left.-P_{L}\right)$ compared with the high $P$ plant root sections $\left(P_{H}\right.$ and $-P_{H}, P=0.012$, Fig. 3c). Nitrogenase efficiency of the $-P_{H}$ root sections were intermediate between the nitrogenase efficiency values of root sections receiving high $P$ fertilizer $\left(P_{H}\right)$ and the low $P$ root section treatments $\left(P_{L}\right.$ and $-P_{L^{\prime}}$, Fig. $\left.3 c\right)$. Finally, the $A R g^{-1}$ root section $\left(\mu \mathrm{mol} \mathrm{C}_{2} \mathrm{H}_{4} \mathrm{~h}^{-1} \mathrm{~g}^{-1}\right.$ biomass, Fig. $3 \mathrm{~d}$ ) did not vary significantly between the four treatment types $(P=0.29)$.

\section{Discussion}

Counter to the long-standing hypothesis that P limits SNF directly by influencing nodule development and function, our study finds evidence suggesting P limits SNF indirectly by limiting plant growth. We found that when $R$. pseudoacacia was grown under low $P$ conditions that SNF was maintained ( $A \mathrm{R} \mathrm{g}^{-1}$ seedling) by increasing nitrogenase efficiency.

\section{b}

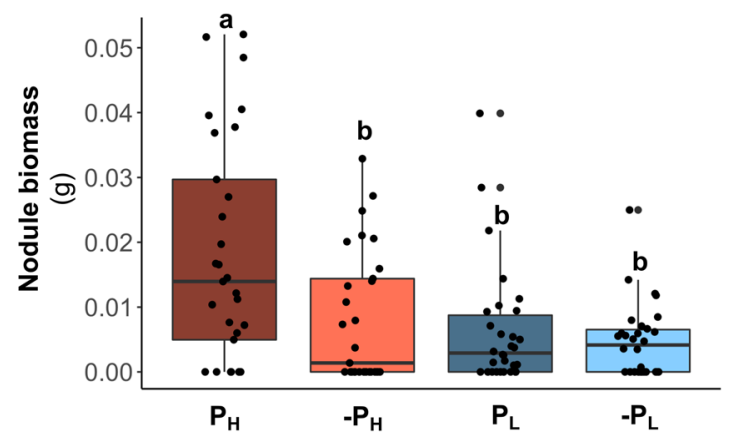

d

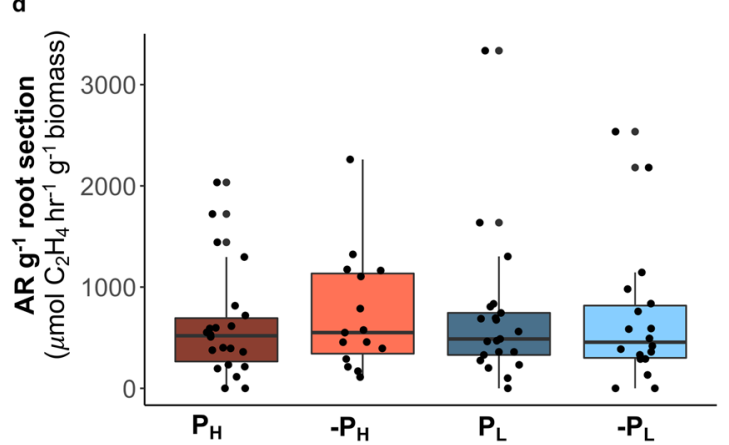

groups. Boxes represent the interquartile range, the line is the median, and the whiskers are the lowest or highest value within 1.5 times the interquartile range. Points represent the values from individual root sections within each treatment. Points were jittered within treatment to prevent overlap

These results document $P$ limitation to plant growth and AR per seedling when $P$ is in low supply, and provide insight into the mechanism by which limitation to SNF can occur in a non-agricultural legume associated with Rhizobia. Seedlings in high $\mathrm{P}$ treatments had higher AR per seedling than those in low $P$ treatments because the high $P$ seedlings had larger seedling biomass supporting greater nodule biomass. Roots grown in patches of soil nutrients did not have more nodule mass $\mathrm{g}^{-1}$ root compared to roots grown in unfertilized soil in either high or low $\mathrm{P}$ treatment groups. This suggests that there may be a limit to how much SNF can be supported by a given mass of root. In order to increase SNF, an increased investment in root and/or plant biomass must be realized. Thus, we infer higher AR per seedling in the high $\mathrm{P}$ treatment resulted from the high $P$ seedlings being able to grow more roots. Since the $\mathrm{AR}^{-1}$ seedling did not differ among $P$ treatments, we conclude (1) higher SNF rates of these seedlings is linked to increases in seedling biomass and, (2) there are mechanisms for smaller seedlings to maintain this $\mathrm{AR}^{-1}$ seedling.

The smaller, low $\mathrm{P}$, plants were able to somewhat compensate for their lower root and nodule biomass 
by increasing nitrogenase efficiency, but not enough to compensate for the advantage in SNF conferred by more total plant and nodule biomass. While our study is one of the first to illustrate this result in non-crop legumes [31], Christiansen and Graham [11] found nodule P concentrations in $P$. vulgaris were not affected by $\mathrm{P}$ limitation despite decreases in $P$ shoot concentrations. This allowed for some genotypes of $P$. vulgaris to maintain SNF even under low $P$ conditions. Further, [31] find similar increases in nitrogenase efficiency for Acacia mangium seedlings grown under low $\mathrm{P}$ conditions, though, these seedlings were inoculated with Bradyrhizobia opposed to Rhizobia. These results support the idea that plants for which whole seedling and root growth is $\mathrm{P}$ limited may increase nitrogenase efficiency to somewhat buffer declining rates of SNF. As demand for $\mathrm{N}$ changes, the SNF rates of a tree can vary throughout its lifetime [38]. Therefore, further study is needed to determine if our findings hold in adult $\mathrm{N}$-fixing legumes as well.

There has been several decades of discussion on the suitability of using ARA to estimate SNF [39-44]. It is important to consider that discussion here, since several of our response variables (nitrogenase efficiency, AR g ${ }^{-1}$ seedling or root, and AR per seedling) were derived from ARA [36, 37]. Our method of ARA [37] includes the excision of nodules and incubation in acetylene, both of which can affect nitrogenase activity $[39,40]$. While the inhibition of nitrogenase activity by acetylene was only minimally observed in our study species using the same inoculum [45], nitrogenase activity could have been affected by nodule excision [39, 43]. Minchin et al. (1986) reported that ARA on nodules still attached to soybean plants grown under low-temperature stress had lower nitrogenase activity compared to ARA on excised nodules in a closed jar (as we did in this experiment), which is contrary to what the authors found at normal growing temperatures. The authors further speculated that other experimental treatments might cause similar treatment "reversal" effects $[39,41]$. Such a treatment "reversal" would invalidate our conclusion that nodule efficiency is increased in seedling in our low $\mathrm{P}$ treatment. However, Ribet and Drevon (1996) grew seedlings under high and low $P$ conditions, compared ARA from excised and attached nodules, and observed no significant difference in acetylene inhibition between excised and attached nodules. In the absence of evidence of acetylene inhibition [45] or of $P$ treatment differentially affecting the disturbance response associated with nodule excision [31], we follow suit with many recent authors $[8,24,30,46-51]$ and acknowledge that ARA does not scale easily with SNF, but can be useful in interpreting differences between experimental treatments as an indication of differences in SNF.

We predicted a stronger localized response of root biomass and SNF to nutrient patches for seedlings grown under $\mathrm{P}$ limitation, similar to previous studies that observed root proliferation into soil nutrient patches [14, 32] or increased SNF on root sections under favorable water conditions or with bacterial symbionts [33,34]. However, we only observed patch proliferation in seedlings grown under high $P$ conditions. Though this patch proliferation was not significant enough to increase the $A R \mathrm{~g}^{-1}$ root section in our high $\mathrm{P}$ seedlings, as we no observed difference in the four split-root treatments for $\mathrm{AR}^{-1}$ root section.

\subsection{Conclusion}

The tradeoff between high nodule biomass (high $\mathrm{P}$ plants) and high nitrogenase efficiency (low P plants) that maintains a relatively constant $A R g^{-1}$ of seedling illustrates the difficulty of using nodule biomass alone to estimate rates of SNF. Further, it highlights the multiple pathways by which legumes may respond to nutrient availability and up- or down-regulate SNF. While we hypothesized that SNF would be upregulated in low $P$ plants encountering a patch of $\mathrm{P}$, only the high $\mathrm{P}$ plants demonstrated a localized response to soil nutrient patches. This result points to a limit on biotic flexibility, albeit in severe conditions relative to what might be encountered in the field (most soils are not silica sand). Further, soil nutrient availability is likely more spatially and temporally variable in a field setting compared to this split-root study. Thus, field tests are needed to determine if (1) localized SNF responses to high soil $P$ patches and (2) increased nitrogenase efficiency are realized. These results will have implications for where SNF occurs on the plant- and landscape-scale and how nutrient limitation controls SNF rates.

Acknowledgements We thank F. Jackson and C. Claussen for their assistance with the growth chambers and greenhouse logistics. Thank you to the Kellner and Porder lab groups for their feedback on the manuscript. We thank R. Thorsness, B. Osborne, and D. Pucci for their help preparing this experiment and caring for the seedlings. We are grateful to J. Winbourne for feedback on experimental design and helpful comments on manuscript draft. We thank D. Menge and R. Arkebauer for providing information on growing Robinia pseudoacacia and nodules for inoculation.

Author contributions L.A.M. and S.P. conceived of and designed the study. L.A.M. performed the research and analyzed the data. L.A.M. and S.P. wrote the manuscript and contributed to revisions.

Funding Institute at Brown for Environment and Society.

Data Availability The data are publicly available on figshare (https ://figshare.com/projects/Soil_nutrient_patch_effect_on_symbi otic_nitrogen_fixation/84179). 
Code availability The code for this manuscript is archived on Github (https://github.com/Imcculloch/Split-Root-2020).

\section{Compliance with ethical standard}

Conflicts of interest The authors declare that they have no conflict of interest.

Open Access This article is licensed under a Creative Commons Attribution 4.0 International License, which permits use, sharing, adaptation, distribution and reproduction in any medium or format, as long as you give appropriate credit to the original author(s) and the source, provide a link to the Creative Commons licence, and indicate if changes were made. The images or other third party material in this article are included in the article's Creative Commons licence, unless indicated otherwise in a credit line to the material. If material is not included in the article's Creative Commons licence and your intended use is not permitted by statutory regulation or exceeds the permitted use, you will need to obtain permission directly from the copyright holder. To view a copy of this licence, visit http://creativecommons .org/licenses/by/4.0/.

\section{References}

1. Cleveland CC, Townsend AR, Schimel DS, Fisher H, Howarth RW, Hedin LO et al (1999) Global patterns of terrestrial biological nitrogen $\left(\mathrm{N}_{2}\right)$ fixation in natural ecosystems. Global Biogeochem Cycles 13:623-645. https://doi.org/10.1029/1999GB900014

2. Vitousek PM, Menge DNL, Reed SC, Cleveland CC (2013) Biological nitrogen fixation: rates, patterns and ecological controls in terrestrial ecosystems. Philos Trans R SocLond B BiolSci 368:20130119. https://doi.org/10.1098/rstb.2013.0119

3. Thilakarathna MS, Raizada MN (2018) Challenges in using precision agriculture to optimize symbiotic nitrogen fixation in legumes: Progress, limitations, and future improvements needed in diagnostic testing. Agronomy 8(5):78. https://doi.org/10.3390/ agronomy 8050078

4. Bergersen FJ (1971) Biochemistry of symbiotic nitrogen fixation in legumes. Annu Rev Plant Physiol 22:121-140. https:// doi.org/10.1146/annurev.pp.22.060171.001005

5. DeHaven G (1910) The fixation of atmospheric nitrogen and the symbiotic nitrogen fixing bacteria. Orgeon Agricultural College, Orgeon

6. Taylor BN, Menge DNL (2018) Light regulates tropical symbiotic nitrogen fixation more strongly than soil nitrogen. Nat Plants 4:655-661. https://doi.org/10.1038/s41477-018-0231-9

7. Wurzburger N, Miniat CF (2014) Drought enhances symbiotic dinitrogen fixation and competitive ability of a temperate forest tree. Oecologia 174:1117-1126. https://doi.org/10.1007/s0044 2-013-2851-0

8. Batterman SA, Wurzburger N, Hedin LO (2013) Nitrogen and phosphorus interact to control tropical symbiotic N2 fixation: a test in ingapunctata. J Ecol 101:1400-1408. https://doi. org/10.1111/1365-2745.12138

9. O'Hara GW (2001) Nutritional constraints on root nodule bacteria affecting symbiotic nitrogen fixation: a review. Aust J Exp Agric. 41(3):417-433. https://doi.org/10.1071/EA00087

10. Weisz PR, Denison RF, Sinclair TR (1985) Response to drought stress of nitrogen fixation (acetylene reduction) rates by field-grown soybeans. Plant Physiol 78:525-530. https://doi. org/10.1104/pp.78.3.525
11. Christiansen I, Graham PH (2002) Variation in di-nitrogen fixation among andean bean (Phaseolus vulgaris L.) genotypes grown at low and high levels of phosphorus supply. Field Crop Res 73(2-3):133-142

12. Vadez V, Lasso JH, Beck DP, Drevon JJ (1999) Variability of N2-fixation in common bean (Phaseolus vulgaris L.) under P deficiency is related to $P$ use efficiency. Euphytica 106:231-242

13. Townsend AR, Cleveland CC, Asner GP, Bustamante MMC (2007) Controls over foliar N:P ratios in tropical rain forests. Ecology 88(1):107-118

14. Hodge A (2004) The plastic plant: root responses to heterogeneous supplies of nutrients. New Phytol 162:9-24. https://doi.org/ 10.1111/j.1469-8137.2004.01015.x

15. Townsend AR, Asner GP, Cleveland CC (2008) The biogeochemical heterogeneity of tropical forests. Trends Ecol Evol 23:424431. https://doi.org/10.1016/j.tree.2008.04.009

16. Menge DNL, Levin SA (2017) Spatial heterogeneity can resolve the nitrogen paradox of tropical forests. Ecology 98:1049-1061. https://doi.org/10.1002/ecy.1733

17. Chadwick KD, Asner GP (2016) Tropical soil nutrient distributions determined by biotic and hillslope processes. Biogeochemistry 127:273-289. https://doi.org/10.1007/s10533-015-0179-z

18. Osborne BB, Nasto MK, Asner GP, Balzotti CS, Cleveland CC, Sullivan BW et al (2017) Climate, topography, and canopy chemistry exert hierarchical control over soil $n$ cycling in a neotropical lowland forest. Ecosystems 20:1089-1103. https://doi.org/10.1007/ s10021-016-0095-7

19. Vitousek PM, Howarth RW (1991) Nitrogen limitation on land and in the sea : how can it occur? Nitrogen limitation on land and in the sea: how can it occur? Biogeochemistry 13:87-115. https://doi.org/10.1007/BF00002772

20. Pons TL, Perreijn K, Van KC, Werger MJA (2006) Symbiotic nitrogen fixation in a tropical rainforest : $\mathrm{N}$ natural abundance measurements supported by experimental isotopic enrichment. New Phytol 173:154-167

21. Robson A (1983) Mineral nutrition. In: Broughton WJ (ed) Nitrogen fixation legumes, vol 3. Claredon Press, Oxford, pp 36-55

22. Binkley D, Senock R, Cromack K (2003) Phosphorus limitation on nitrogen fixation by facaltaria seedlings. For Ecol Manag 186:171-176. https://doi.org/10.1016/S0378-1127(03)00240-8

23. Augusto L, Delerue F, Gallet-Budynek A, Achat DL (2013) Global assessment of limitation to symbiotic nitrogen fixation by phosphorus availability in terrestrial ecosystems using a meta-analysis approach. Global Biogeochem Cycles 27:804-815. https:// doi.org/10.1002/gbc.20069

24. Nasto MK, Osborne BB, Lekberg Y, Asner GP, Balzotti CS, Porder $S$ et al (2017) Nutrient acquisition, soil phosphorus partitioning and competition among trees in a lowland tropical rain forest. New Phytol. https://doi.org/10.1111/nph.14494

25. Magadlela A, Kleinert A, Dreyer LL, Valentine AJ (2014) Lowphosphorus conditions affect the nitrogen nutrition and associated carbon costs of two legume tree species from a Mediterranean-type ecosystem. Aust J Bot 62:1-9. https://doi. org/10.1071/BT13264

26. Sanginga N, Okogun JA, Akobundu IO, Kang BT (1996) Phosphorus requirement and nodulation of herbaceous and shrub legumes in low P soils of a Guinean savanna in Nigeria. Appl Soil Ecol 3:247-255. https://doi.org/10.1016/0929-1393(95)00083-6

27. Pereira PAA, Bliss FA (1987) Nitrogen fixation and plant growth of common bean (Phaseolus vulgaris L.) at different levels of phosphorus availability. Plant Soil 104:79-84. https://doi. org/10.1007/BF02370628

28. Chaudhary MI, Adu-Gyamfi JJ, Saneoka H, Nguyen NT, Suwa $R$, Kanai $S$ et al (2008) The effect of phosphorus deficiency on nutrient uptake, nitrogen fixation and photosynthetic rate in 
mashbean, mungbean and soybean. ActaPhysiol Plant 30:537544. https://doi.org/10.1007/s11738-008-0152-8

29. Jakobsen I (1985) The role of phosphorus in nitrogen fixation by young pea plants (Pisum sativum). Physiol Plant 64:190-196. https://doi.org/10.1111/j.1399-3054.1985.tb02334.x

30. Dovrat G, Masci T, Bakhshian H, MayzlishGati E, Golan S, Sheffer E (2018) Drought-adapted plants dramatically downregulatedinitrogen fixation: evidences from Mediterranean legume shrubs. J Ecol 106:1534-1544. https://doi.org/10.1111/1365-2745.12940

31. Ribet J, Drevon JJ (1996) The phosphorus requirement of $\mathrm{N}_{2}$-fixing and urea-fed Acacia mangium. New Phytol 132:383390. https://doi.org/10.1111/j.1469-8137.1996.tb01858.x

32. Drew MC (1975) Comparison of the effects of a localized supply of phosphate, nitrate, ammonium and potassium on the growth of the seminal root system, and the shoot, in barley. New Phytol 75:479-490

33. Marino D, Frendo P, Ladrera R, Zabalza A, Puppo A, Arrese-Igor $C$ et al (2007) Nitrogen fixation control under drought stress localized or systemic? Plant Physiol 107:097139. https://doi. org/10.1104/pp.107.097139

34. Batstone RT, Dutton EM, Wang D, Yang M, Frederickson ME (2016) The evolution of symbiont preference traits in the model legume Medicago truncatula. New Phytol. https://doi. org/10.1111/nph.14308

35. Ishizuka J (1982) Characteristics of molybdenum absorption and translocation in soybean plants. Soil Sci Plant Nutr 28:63-77. https://doi.org/10.1080/00380768.1982.10432372

36. Hardy RWF, Burns RC, Holsten RD (1973) Applications of the acetylene-ethylene assay for measurement of nitrogen fixation. Soil BiolBiochem 5:47-81. https://doi.org/10.1016/00380717(73)90093-X

37. Sullivan BW, Smith W, Townsend A, Nasto MK, Reed S, Chazdon $R$ et al (2014) Spatially robust estimates of biological nitrogen (N) fixation imply substantial human alteration of the tropical N cycle. ProcNatlAcadSci 111:8101-8106

38. Jacobs SM, Pettit NE, Naiman RJ (2007) Nitrogen fixation by the savanna tree Philenoptera violacea (Klotzsch) Schrire (apple leaf) of different ages in a semi-arid riparian landscape. S Afr J Bot 73:163-167. https://doi.org/10.1016/j.sajb.2006.09.001

39. Minchin FR, Sheehy JE, Witty JF (1986) Further errors in the acetylene reduction assay: effects of plant disturbance. J Exp Bot 37:1581-1591. https://doi.org/10.1093/jxb/37.10.1581

40. Witty JF, Minchin FR (1988) Measurement of nitrogen fixation by the acetylene reduction assay myths and mysteries. In: Beck DP, Materon LA (eds) Nitrogen fixation by legumes in Mediterranean agriculture. Springer, Dordrecht, pp 331-344. https:// doi.org/10.1007/978-94-009-1387-5_33

41. Minchin FR, Witty JF, Mytton L (1994) Reply to measurement of nitrogenase activity in legume root nodules: in defense of the acetylene reduction assay. Plant Soil 158:151-162. https://doi. org/10.1007/BF00009490

42. Witty JF, Minchin FR, Sheehy JE, Ines MM (1984) Acetyleneinduced changes in the oxygen diffusion resistance and nitrogenase activity of legume root nodules. Ann Bot 53:13-20. https ://doi.org/10.1093/oxfordjournals.aob.a086663

43. Vessey JK (1994) Measurement of nitrogenase activity in legume root nodules: In defense of the acetylene reduction assay. Plant Soil 158:151-162. https://doi.org/10.1007/BF00009490

44. Unkovich M, Herridge D, Peoples M, Cadisch G, Boddey B, Giller $\mathrm{K}$ et al (2008) Measuring plant-associated nitrogen fixation in agricultural systems. Meas plant-associated nitrogen fxation Agric Syst. https://doi.org/10.1071/AR9940119

45. Bytnerowicz TA, Min E, Griffin KL, Menge DNL (2019) Repeatable, continuous and real-time estimates of coupled nitrogenase activity and carbon exchange at the whole-plant scale. Methods Ecol Evol 10:960-970. https://doi.org/10.1111/2041-210X.13186

46. Trierweiler AM, Winter K, Hedin LO (2018) Rising CO2 accelerates phosphorus and molybdenum limitation of N2-fixation in young tropical trees. Plant Soil. 429:363-373. https://doi.org/10.1007/ s11104-018-3685-7

47. Nasto MK, Alvarez-Clare S, Lekberg Y, Sullivan BW, Townsend AR, Cleveland CC (2014) Interactions among nitrogen fixation and soil phosphorus acquisition strategies in lowland tropical rain forests. Ecol Lett 17:1282-1289. https://doi.org/10.1111/ ele.12335

48. Soper FM, Nasto MK, Osborne BB, Cleveland CC (2018) Nitrogen fixation and foliar nitrogen do not predict phosphorus acquisition strategies in tropical trees. J Ecol. 107(10):1-9. https://doi. org/10.1111/1365-2745.13044

49. Dovrat G, Sheffer E (2019) Symbiotic dinitrogen fixation is seasonal and strongly regulated in water-limited environments. New Phytol 221:1866-1877. https://doi.org/10.1111/nph.15526

50. Dovrat G, Bakhshian H, Masci T, Sheffer E (2020) The nitrogen economic spectrum of legume stoichiometry and fixation strategy. New Phytol. 227(2):0-2. https://doi.org/10.1111/nph.16543

51. Zheng M, Li D, Lu X, Zhu X, Zhang W, Huang J et al (2016) Effects of phosphorus addition with and without nitrogen addition on biological nitrogen fixation in tropical legume and nonlegume tree plantations. Biogeochem 131:65-76. https://doi. org/10.1007/s10533-016-0265-x

Publisher's Note Springer Nature remains neutral with regard to jurisdictional claims in published maps and institutional affiliations. 